\title{
Mobile Genetic Elements and Natural Gene Transfer in Rumen Microbial Ecosystem
}

\author{
Haben Fesseha ${ }^{1 *}$ \\ $1 *$ School of Veterinary Medicine, Wolaita Sodo University, PO box 138, Wolaita Sodo, Ethiopia \\ 2.College of Veterinary Medicine, Addis Ababa University, Ethiopia PO box 34, Bishoftu, Ethiopia
}

\begin{abstract}
As technology is going be modern different changes that occur in the nature become studied. Rumen microbes especially rumen bacteria play a vital role in utilization of ruminants feed. Without rumen microbe's rumen can't function correctly. So, when we feed our animals, we are also feeding rumen microbes which convert the plant fiber to VFA which used by ruminants as an energy source for maintenance and production. Through the process these microbes change in their genetic structure and function because of natural gene transfer which is mediated by movable genetic elements like bacteriophage, plasmid, transposons and other segments. In this review prokaryotes which include bacteria and archae have got large cover than eukaryotes because most significant changes in rumen are carried by those organisms. HGT is the way to perform this function because it enables bacteria to respond and adapt to their environment much more rapidly by acquiring large DNA sequence from other bacterium in a single transfer and mechanisms of bacterial gene transfer include transformation, transduction and conjugation. So this event has an impact on the microbe themselves, for the rumen ecosystem, the animal and the environment where these changes are related. These changes include antibiotic resistance, better conversion of feeds and effects in methane and ammonia production.
\end{abstract}

Keywords: Horizontal Gene Transfer, Prokaryotes, Rumen. Rumen Microbes

DOI: $10.7176 /$ ALST/78-03

Publication date: February $29^{\text {th }} 2020$

\section{INTRODUCTION}

The rumen is a complex microbial ecosystem and it played a critical role in sustainable agriculture throughout human life. Microorganisms in the rumen perform essential fermentation, including the conversion of plant fiber to small molecules, such as volatile fatty acids (VFA) and vitamins, for the production of meat and milk for human consumption, by influencing the host's nutrition. In addition, rumen microorganisms modulate host immunity and enhance host resistance to invading pathogens (Sparks and Connor, 2011). Additionally, certain bacteria detoxify naturally occurring compounds in the diet that are harmful to the host (Gregg, 1995).

Regarding of maximizing productivity and improving the overall host health via manipulating the rumen and its microbial ecosystem, microbiologists, and physiologists have been studying the rumen for many years. When rumen microorganisms are disturbed or absent there can be a cascade of detrimental effects on animal health and productivity. Understanding of complex microbial communities' function and interactions within their environment represents a major challenge for rumen microbiologists still today. Advances in molecular biology and genomics offer new opportunities to conduct a full examination of the structure and function of rumen microbial communities (Sirohi et al., 2012).

A firm knowledge of major components of rumen microbial ecosystems and their interactions is a prerequisite to the development of strategies for ruminal manipulation, such as increasing the efficiency of fiber digestion (Edwards, 2007).

Mobile genetic elements (MGEs) are segments of DNA that encode enzymes and other proteins that mediate the movement of DNA within genomes (intracellular mobility) or between bacterial cells (intercellular mobility). Intercellular movement of DNA takes three forms in prokaryotes: transformation, conjugation and transduction (Burrus and Waldor, 2009).

Gene transfer system is a powerful tool in genetic analysis, and it is so essential for the formation of recombinant rumen bacteria. Gene transfer system is now developed and refined for prominent species. Gene transfer in general sense can be regarded as prokaryotic sex or a mechanism to "mix genes" between the community members. However, the process of prokaryotic gene transfer is dramatically different from sex as it occurs in eukaryotes. First, it is usually not a component of the cellular life cycle in prokaryotes. This might be contested in the case of transformation, as the genes for competence development undergo activation at discreet times in the growth cycle of batch cultures (Smith et al., 1981).

There is a need of research to know how rumen microorganisms (MOs) live in their niche as it is critical for the productivity and efficient feed utilization of rumen and this review is believed to be essential to give highlights on these issues. Therefore, this review paper deals about the mobile genetic elements and natural gene transfer in rumen microbial ecosystem and its effect of rumen bacterial gene transfer 


\section{RUMEN ECOSYSTEM}

The ruminant digestive system is containing four compartments named as reticulum, rumen, omasum, and abomasum. From these compartments the rumen is the main where the major fermentation processes are held (Tharwat et al., 2012). Enzymes are present in the rumen which produced by microorganisms. Rumen is called fermentation vat because these enzymes are used to digest and ferment food eaten by ruminants (Aschenbach et al., 2011).

Rumen is a complex ecosystem where nutrients digested anaerobically by the microorganisms such as bacteria, protozoa, and fungi. The main end products of fermentation are volatile fatty acids (VFAs) mainly (acetate, propionate and butyrate) and microbial biomass, which are used by the host ruminant. The symbiotic relationship between microorganisms and the host animal allows ruminants to digest diets rich in fiber and low in protein. In the rumen the environment favors the microorganisms to provide the enzymes necessary to digest the nutrients. Ruminants have the ability to convert the low-quality fibrous materials into products such as meat, milk and fibers, which are useful to humans. The ability of ruminal microorganisms to produce the enzymes necessary for fermentation processes allows ruminants to efficiently obtain the energy contained in forages (Burns, 2008).

However, the ruminal fermentation process is not completely efficient because it produces some final products such as methane gas (Kingston-Smith et al., 2012) and excess ammonia (Russell and Mantovani, 2002). Ruminants such as cattle, sheep, and goats have evolved to use fibrous food efficiently (Oltjen and Beckett, 1996). The ruminal microorganisms allows them to use cellulose as an energy source without requiring external sources of vitamin B complex (Russell and Mantovani, 2002) or essential amino acids because ruminal MOs able them to produce such products (Cole et al., 1982). Thus, a symbiotic relationship exists within the rumen providing the necessary environment for the establishment of microorganisms and substrates required for their maintenance. In reverse the microorganisms also allow nutrients to the host ruminant to generate energy (Russell and Rychlik, 2001).

\section{Ruminal micro-organisms}

\section{Ruminal Bacteria}

The rumen contains a variety of bacterial genera (Table 1), which constitute the majority of the microorganisms that live in anaerobic environment (Pitta et al., 2010). The competition between bacteria in the rumen is determined by several factors, among which are the preference for certain substrates, energy requirements for maintenance, and resistance to certain metabolism products that can be toxic (Russell et al., 1979). Some common rumen bacteria are listed in Table 1.

\section{Ruminal Fungi}

Fungi represent a small proportion of the biomass in the ruminal ecosystem (Jenkins et al., 2008), but they do have a role in the digestion of food consumed by the ruminant (Nam and Garnsworthy, 2007). Ruminal fungi are able to produce enzymes that hydrolyze cellulose and xylans (Bernalier et al., 1992) (Table 2).

\section{MOBILE GENETIC ELEMENTS (MGEs)}

Ever since, geneticists have found various genetic events at which some genetic elements are capable of moving around the genome actively or passively, these genetic elements now referred to as mobile genetic elements (MGEs) (Frost, 2005).

\section{Plasmid}

It is a collection of functional genetic modules that are organized into a stable, self-replicating independently exists or 'replicon', which is smaller than the cellular chromosome and which usually does not contain genes required for essential cellular functions. The classic plasmids are covalently closed, circular double-stranded DNA molecules, but linear double-stranded DNA plasmids have been found in an increasing number of species (Stewart et al., 2005).

Plasmids contain genes essential for their function and existence in a cell. Some of them possess genes which control plasmid stability managing division and transfer functions by conjugation (Couturier et al., 1988). These genes can be found rather in larger plasmids than in smaller ones. However, small plasmids can be mobilized and transferred to another cell by larger, conjugated plasmids (Tompkins, 1985). Plasmids are related with numerous biological functions of bacteria: transfer of genetic material by conjugation, bacteriocin (antibiotic produced by bacteria) and colicin (Col-plasmids) production, generation of antibiotics, heavy-metals resistance, antibiotic resistance (R plasmids), UV emission resistance (UV), production of enterotoxins $E$. coli, production of chemolysine, camphor metabolism, causes malignancy in plants, restriction, and modification (Cohen, 1976). 


\section{Bacteriophages}

Bacteriophages (phages) are bacteria attacker viruses, which are obligate intracellular parasites of bacteria. The total global population of tailed phages, being the most abundant organisms on Earth, is estimated in the order of $10^{31}$ viral particles (Waldor et al., 2005).

The genomes of phages can be composed of either DNA or RNA which can be single- or double-stranded and can range in size from a few to several $100 \mathrm{~kb}$. Their characteristic essential genes comprise specific replicase genes, genes encoding phage components that illegally take the host cell replicative machinery, and genes encoding the proteins that package DNA in a protein coat (capsid). Virulent bacteriophages replicate vigorously and lyse the host bacteria but the moderate (temperate) bacteriophages is lysogeny which is quiescent and non-lytic growth mode. These viruses can integrate into the host genome and then be vehicles for horizontal gene transfer (Canchaya et al., 2003).

\section{Integrative conjugative elements (ICE)}

Self-transferable conjugative elements that integrate into the genome of new hosts like temperate bacteriophages; may promote the mobilization of genomic islands by utilizing conserved integration sites (Burrus and Waldor, 2004). All together, this broad group of MGEs is called integrative and conjugative elements (Wackernagel and Brigulla, 2010). ICEs can integrate into host chromosomes, and normally a single stranded form is generated during their conjugative transfer (Wozniak and Waldor, 2010).

\section{Genomic island}

They are large chromosomal regions acquired by horizontal transfer that are flanked by repeat structures and contain genes for chromosomal integration and excision (Dobrindt et al., 2004). In many bacterial pathogens pathogenicity islands which are mobile genetic elements contribute to rapid changes in virulence potential are known to have contributed to genome evolution by horizontal gene transfer. Increasing evidence indicates that equivalent elements in non-pathogenic species, genomic islands, are important in the evolution of these bacteria, influencing traits such as antibiotic resistance, symbiosis and fitness, and adaptation in general. (http://www.nature.com/nrmicro/journal/v2/n5/full/nrmicro884.html).

\section{Transposable elements}

Transposable elements (TEs) are defined as DNA sequences that are able to move from one location to another in the genome. TEs have been identified in all organisms, prokaryotic and eukaryotic, and can occupy a high proportion of a species' genome (Martín and Jose, 2010).

Transposable elements can be divided into two major classes based on method of transposition. The first one is Retrotransposons (class 1) which use reverse transposase to make RNA intermediate for transposition, encode an integrase and reverse transcriptase for transposition and found in viruses. The second one is Transposons (class 2) in which DNA fragments transpose directly from DNA segment to DNA segment: Producing a DNA copy that transposes (replicative transposition) or, cut/paste into a new locus (conservative transposition), encode a transposase for transposition, can carry additional genes and found in eukaryotes and prokaryotes (https://www.ebi.ac.uk/interpro/potm/2006_12/Page2.htm).

\section{Integrones}

Integrones are genetic elements that capture promoter less gene cassettes at an attachment site downstream of a promoter, by action of the integrase encoded on the integron; frequently associated with transposons and conjugative plasmids (Hall and Collis, 1995).

\section{HORIZONTAL GENE TRANSFER: A MECHANISM OF GENE TRANSFER BETWEEN MICROORGANISMS}

Gene transfer is a natural phenomenon that can provide microorganisms with the means to survive under unfavorable environmental conditions. In the last few years the sequencing of entire microbial genomes has shown that microbes are mosaics of acquired genes, suggesting that horizontal gene transfer also known as lateral gene transfer has been a major driving force in microbial evolution (Lorenz and Wackernage, 1994). It helps microorganisms to rapidly acquire new metabolic capabilities and adapt to environmental changes (Wozniak and Waldor, 2010). Most genes involved in HGT are associated with pathogenesis, symbiosis, metabolism, and antibiotic resistance (Babic et al., 2011) HGT was shown to occur between both closely and distantly related organisms (Creevey et al., 2011)

The three main mechanisms of prokaryotic gene transfer are transformation, conjugation, and transduction, but it is likely that the three mechanisms combine in natural environments such as gut. Transformation involves the uptake and expression of genes encoded by exogenous, unprotected DNA from the environment. This could be chromosomal DNA fragments, plasmids or transposons. Transformation is a normal, physiological function 
of some bacteria that express ability to uptake DNA at some time in their life cycle (Lorenz and Wackernage, 1994). Conjugation is a plasmid or transposon encoded mechanism of gene transfer that requires contact between cells (Morrison, 1996).

\section{Natural genetic transformation}

Natural genetic transformation is the active uptake of free DNA by bacterial cell themselves and then heritable incorporation of its genetic information. Since the famous discovery of transformation in Streptococcus pneumoniae by Griffith in 1928 and the demonstration of DNA as the transforming principle by Avery and coworkers in 1944, cellular processes involved in transformation have been studied extensively by in vitro experimentation with a few transformable species (Lorenz and Wackernagel, 1994).

Natural transformation happen when cells enter into a transient physiological state called competent or the ability of a cell to take naked DNA. The specific triggers turning cells into competent are not clear for many species. The naked DNA from extracellular environment can be chromosomal DNA, plasmid DNA or viral DNA. They are derived from dead prokaryotic/eukaryotic cells or viral particles. The size of uptake DNA can range from few hundred nucleotides to more than 55,000 nucleotides. Most time, only one strand of the uptake DNA is transported into cytoplasm, while the other strand is degraded outside cytoplasm (Wackernagel and Brigulla, 2010).

When the uptake DNA binds to DNA receptor proteins of competent cells, transformation starts. Then the transport machinery employs a cell-envelope-spanning structure, which consists of type IV pilus and type II secretion systems, and its coupled cytoplasmic membrane DNA translocation complex to import the single stranded uptake DNA into cytoplasm. The cytoplasmic membrane DNA translocation complex includes DNA receptor protein, channel protein and ATP-binding protein (Chan and Dubnau, 2004).

The imported single stranded DNA can be integrated into the host genome through homologous recombination means between very similar DNA sequences or through rare illegitimate recombination which is nonhomologous. The homologous recombination relies on RecA protein and its analogs, while the illegitimate recombination does not. Other proteins involved in the recombination process include helicases, DNases, DNA binding proteins, DNA polymerase and ligase. If the imported single stranded DNA is derived from plasmid, it can go on plasmid reconstitution (Wackernagel and Brigulla, 2010; Chan and Dubnau, 2004).

So this process is simply defined as: After death or cell lyses, some bacteria release their DNA into the environment and other bacteria, generally of the same species, can come into contact with these fragments, take them up and incorporate them into their DNA by recombination. But any DNA that is not integrated into the chromosome will be degraded. The genetically transformed cell is called a recombinant cell because it has a different genetic makeup than the donor and the recipient (Madigan et al., 2000). The mechanism is as shown in the figure 2 .

\section{Transduction}

Transduction is a way of DNA acquisition by which non-viral DNA can be transferred from an infected host bacterium to a new host via infectious or non infectious virus particles (Wommack and Colwell, 2000).

Two different strategies were identified to contribute to this horizontal transfer of genes between different host bacteria. In generalized process any bacterial gene may be transferred to another bacterium via a bacteriophage, and typically carries only bacterial DNA and no viral DNA. In essence, this is the packaging of bacterial DNA into a viral envelope. This may occur in two main ways,recombination and heedful packaging.(https://www.boundless.com/microbiology/textbooks/boundlessmicrobiology-textbook/microbial-genetics-7/genetic-transfer-in-prokaryotes-81/bacterial-transduction-443$\underline{6859 /)}$.

General Transduction takes steps: first a phage attaches to cell wall of bacterium and injects DNA, then the bacterial chromosome is broken down and biosynthesis of phage DNA and protein occurs. Sometimes bacterial DNA can be packaged into the virus instead of phage DNA. This phage is defective (can't destroy another host cell) because it does not carry its own genetic material. After that the cell lyses, releasing viruses. Finally, the phage carrying bacterial DNA infects another cell as it is in figure 3 (Madigan et al., 2000).

In contrast, in specialized transduction, the transducing viral particle contains a hybrid molecule with a part of the phage genes and some bacterial genes (Arber et al., 1960). Specialized transduction is the process by which a restricted set of bacterial genes are transferred to another bacterium. The genes that get transferred (donor genes) depend on where the phage genome is located on the chromosome. Specialized transduction occurs when the prophage cut imprecisely from the chromosome so that bacterial genes lying adjacent to the prophage are included in the excised DNA. The excised DNA is then packaged into a new virus particle, which can then deliver the DNA to a new bacterium, where the donor genes can be inserted into the recipient chromosome or remain in the cytoplasm, depending on the nature of the bacteriophage (Lorenz et al., 1994).

Specialized Transduction also have its own steps: At the beginning remember that in the lysogenic cycle, 
phage DNA can exist as a prophage integrated in the bacterial chromosome. Occasionally when the prophage exits it can take adjacent bacterial genes with it. Then the phage DNA directs synthesis of new phages. This phage particles carry phage DNA and bacterial DNA. Then the cell lyses, releasing the phages. After that a phage carrying bacterial DNA infects another cell. In which the joined phage and bacterial DNA circularize. Finally, along with the prophage, bacterial DNA integrayes with the recipient chromosome by a cross over event which forms a recombinant cell (Madigan et al., 2000) (Figure 3).

\section{Bacterial Conjugation}

Conjugation is a process of the transfer of DNA from a donor to a recipient cell through cell-to-cell contact. The DNA transferred by conjugation can be conjugative plasmids, conjugative transposons, or the recent years discovered varied MGEs which are capable of similar DNA transfer processes as conjugative plasmids and transposons (Wackernagel and Brigulla, 2010).

This process usually is regulated by genes carried by conjugative plasmids, which code creation of pili which are necessary for a contact between cells. It may be possible that there are more genetically different systems of conjugation (Willetts and Wilkins, 1984).

This mechanism requires the presence of a special plasmid called the $\mathrm{F}$ plasmid. Bacteria that have a $\mathrm{F}$ plasmid are referred to as $\mathrm{F}+$ or male. Those that do not have an F plasmid are F- or female. This can give bacterium new genes that may help it survive in a changing environment (Madigan et al., 2000).

During conjugational transfer of DNA the following occurs: Forming of "a nick" and beginning of DNA transfer at the origin of transfer (oriT), then segregation of two plasmid DNA chains in which transferring one of the chains into recipient cell, then conjugational synthesis of complete plasmid DNA both in a donor and a recipient cells, finally creation of circular forms of plasmid replicons as shown in the next figure. Thus, plasmid replication process can be divided into three stages: initiation, elongation, and termination. Initiation is catalyzed most frequently by one or a few plasmid-encoded initiation proteins that recognize plasmid-specific DNA sequences and determine the point from which replication starts (the origin of replication) (Del Solar et al., 1998). Some plasmids can integrate reversibly into the bacterial chromosome. An integrated plasmid is called an episome and the cell is called an Hfr cell (high frequency of recombination cell) (Madigan et al., 2000) (Figure 4).

\section{Horizontal Gene Transfer between Eukaryotes and Prokaryotes}

Although this process is assumed to be much less frequent than HGT between bacteria numerous cases of HGT from bacteria to eukaryotes have been demonstrated. The early evolution of eukaryotes was marked by endosymbiotic (symbiosis in which a symbiont dwells within the body of its symbiotic partner) events leading to permanent acquisition of major organelles, e.g., mitochondria that originated from proteobacteria and plastids that originated from cyanobacteria, followed by organelle-to-nucleus gene transfer, usually referred to as endosymbiotic gene transfer (EGT) (Archibald, 2015).

Episodic gene transfer via EGT has a demonstrated evolutionary significance, the importance of HGT in the evolution of eukaryotes is still debated (Syvanen, 2012). A recent study analyzing a large number of protein sequences from bacterial and eukaryotic organisms indicates that gene inheritance in eukaryotes is predominantly vertical and suggests that HGT occurs only occasionally and that sequences acquired by HGT do not accumulate in eukaryotic genomes and do not contribute to long-term evolution of gene content ( $\mathrm{Ku}$ et al., 2015). However, it is generally agreed that HGT from prokaryotes to eukaryotes does occur to a certain extent and, in some cases, plays a role in adaptive evolution (Schönknecht et al., 2014).

\section{GENE TRANSFER IN RUMEN BACTERIA}

In genetic analysis gene transfer systems are important tools and are essential for construction of recombinant rumen bacteria. Gene transfer system have now been developed and refined for prominent species of ruminal bacteria including $B$. fibrisolvens, $P$. ruminicola, $R$. albus, $S$. ruminantem and $P$. bryantii also called $B$.ruminicola (Forsberg et al., 1997). Bacteriophage has also been studied, but none have been used for genetic transfer (Selinger et al., 1996). So there presence met the necessary requirements for conjugation and transduction. Natural transformation on the other hand seems less likely, given the high nucleolytic activity of the ruminal fluid (Flint and Thomson, 1990).

However, these are only the technical requirements for the gene transfer. But we should also consider whether gene transfer could have any impact on the rumen function. Despite the circadian and other changes in rumen population brought about by changes of the diet, this community must always be able to supply the animal with volatile fatty acids and bacterial protein. Therefore if the degradation of plant fibre and growth on its products, which is dominated by the bacteria, demands a highly specialized and equilibrated community, then gene transfer would be discouraged between its functionally distinct members. However, there is a daily influx of soil and plant microorganisms into the rumen which remain in the rumen for a given amount of time. They are 
ingested with food and even being only transient residents they could serve as donors of novel genes for the rumen environment (Peterka, et al., 2000).

\section{Evidence for Gene Transfer in the Rumen}

Laboratory transfer of genetic elements by conjugation and natural transformation

These experiments show that the potential for natural gene transfer exists. These experment focused on the transfer of tetracycline resistance genes, and succeeded to transfer the tetracycline resistance in anaerobic mating between two species of ruminal Prevotella. The gene for tetracycline resistance was co transferred with a 19.5 kbp plasmid pRRI4 which was concluded to carry the tetQ gene (Flint et al., 1988). Although the transfer was of the conjugative type, the plasmid pRRI4 was up to now not shown to code for genes involved in transfer. Therefore, the transfer could have been mediated by some other chromosomal mobilizing element. This was also suspected by when Prevotella bryantii successfully acted as a donor of an E. coli-Bacteroides-Prevotella shuttle vector pRDB5 that needed to be mobilized for the transfer (Shoemaker et al., 1992).

The transfer of tetracycline resistance was also shown between Butyrivibrio strains. It was not plasmid associated and it also resulted in a change of the chromosomal restriction pattern observed with PFGE. This suggested the existence of a tetracycline carrying mobile chromosomal element with the size of 40-60kbp (Scott et al., 1997). Not only chromosomal elements, but presumably also parts of the chromosomes can be transferred in such way. This was shown by moving the ability to utilize lactate from a lactate utilizing to a lactate-nonutilizing strain of Selenomonas ruminantium with simple mating procedure (Gilmour et al., 1996).

The significance of transient members of rumen microflora as potential donors of various genes was demonstrated by Flint and Scott (1995) who showed that E. coli strains isolated from the rumen can successfully exchange their plasmids by conjugation in anaerobic conditions in a medium that included whole rumen fluid. Presumably they can also conjugate with related bacteria, starting the multi-stage intergenera transfer that can lead to the transfer of genes to phylogenetically distant organisms inhabiting the rumen. Recently Streptococcus bovis, an important member of the ruminal microflora, was shown to be capable of natural transformation with plasmids in normal culture medium. However, transformation was prevented by ovine ruminal fluid and saliva, being detected at 100 fold dilution of the rumen fluid in the medium (Mercer et al., 1999).

Steady progress is being made to develop more sophisticated vectors, such as the suicide vector system for chromosomal integration in S. bovis (Brooker et al., 1995). This suicide vector used to assess the importance of the intracellular-amylase in $S$. bovis. A trasformant lacking intracellular amylase in activity exhibited a slower growth rate, thereby demonstrating the importance of amylase in metabolism. It was speculated that intracellular amylase may have role in either maltose or glucose transport (Brooker and McCarty, 1997).

\section{Gene transfer between rumen bacteria and fungi}

Inter-genera and even inter-kingdom transfer of microbes are more reported than exchange between closely related species. The latter is probably more common but hard to follow, since it does not result in a gene whose structure (introns, codon usage) is foreign to the recipient. It was reported by several authors that the genes coding for glycosyl hydrolases $(\mathrm{GH})$ from the rumen fungi of the genera Neocallimastix, Piromyces and Orpinomyces contained no introns and showed surprising homology with genes that code for rumen bacterial glycosyl hydrolases. This suggested that a gene transfer between bacteria and fungi occurred (Peterka et al., 2000).

In this fact recently conducted a survey of rumen fungal GH sequences. They compared the codon usage of GH genes to other fungal enzymes and also F. succinogenes glycosyl hydrolase genes. The fungal GH genes formed a cluster separate from both other group, however one rumen fungal sequence was clustered together with Fibrobacter genes. The biased codon usage is a general feature of highly expressed genes. But since other non-GH genes from fungi which were included in the analysis are also highly expressed, this could not be the reason for separate clustering of fungal GH genes (Garcia-Vallve et al. 2000, Peterka et al., 2000).

\section{Gene transfer and its impact on methanogensis and ammonia production}

Horizontal gene transfer and genome evolution in Methanosarcina

Methane production has been estimated to result in a loss of 2 to $12 \%$ of feed energy from cattle and is thought to be most serious in forage-fed animals. Reduction or elimination of methanogenesis in domestic livestock has been touted as a way of improving animal production and may marginally contribute to control of anthropogenic release of methane, a potent greenhouse gas (Johnson and Johnson, 1995).

Genomes of Methanosarcina spp. are among the largest archaeal genomes. One suggested reason for that is massive horizontal gene transfer (HGT) from bacteria. Genes of bacterial origin may be involved in the central metabolism and solute transport, in particular sugar synthesis, sulfur metabolism, phosphate metabolism, DNA repair, transport of small molecules etc. Horizontally transferred (HT) genes are considered to play the key role in the ability of Methanosarcina spp. to inhabit diverse environments (Sofya et al., 2015). 
Horizontal transfer of a short operon from Clostridia was shown to dramatically change Methanosarcinales (Fournier et al., 2007) or Methanosarcinaceae (Fournier et al., 2009) metabolic capabilities, and allowed these organisms to use methyl compounds as substrates for methanogenesis (Sofya et al., 2015).

\section{Effect of gene transfer in ammonia production}

Ammonia is a key metabolite in rumen nitrogen metabolism. The data reported by a number of workers have clearly shown that a large proportion $(60-80 \%)$ of the nitrogen incorporated into microbial protein passes through the rumen ammonia pool (Pawel et al., 1981).

The Rh50 proteins belong to the family of ammonia. Ammonia permeases increase the permeability of $\mathrm{NH}_{3} / \mathrm{NH}_{4}{ }^{+}$across cell membranes and are assumed to be involved in excretion of toxic ammonia and in the maintenance of pH homeostasis. The RH50 genes are widespread in eukaryotes but absent in land plants and fungi, and remarkably rare in prokaryotes. The evolutionary history of RH50 genes in prokaryotes is just beginning to be unveiled. A molecular phylogenetic approach suggests horizontal gene transfer (HGT) as a primary force driving the evolution and spread of RH50 among prokaryotes. (Matassi, 2017).

\section{CONCLUSION AND RECOMMENDATIONS}

Genomic informations are transmitted between organisms by vertical transmission, from the parents to their offspring via germline or cell division. But in other means it can transfer also by horizontal transmission which is directly between organisms. Now a day HGT is a cause of major evolutionary force among prokaryotes and it influence them to alter their mechanisms because it is the recombination of two different DNA segments. Indeed, several genome-wide studies have shown that HGT occurs at a high frequency between prokaryotic species, particularly if they are closely related or if they coexist in the same habitat or community, which provides many opportunities for DNA transfer. HGT permits fast acquisition of a new function important for species adaptation and survival rather than evolution via gene duplications and mutations. As a rumen is a place of many bacterias this natural phenomena is also seen, and provide both positive and negative influence.

Therefore, in the base of the above conclusion the listed recommendations are stated

- Further studies must be continued in order to know well about nature which includes rumen ecosystem and its divers environment.

- Enhancing the influence of rumen microorganisms gene transfer specially in bacterias that used for fermentation of cellulose, amylase, lactose and other compounds, and also reduce the side effects that caused by gene transfer in the efficiency of these compounds.

- Reduce the negative effect of rumen gene transfer in the formation of methane gas and other unnecessary products which have a side effect on the animal health and productivity and further in the environmental ecosystem.

- Adding of bacterias which cause important gene transfer in rumen for better feed utilization.

\section{REFERENCES}

Arber, W., Kellenberger, G. and Weigle, J. (1960): The defectiveness of Lambda transducing phage. In: Papers on Bacterial Genetics; Adelberg, E. A., (Ed.) Little, Brown and Co., New York, NY, USA. Pp. 224-229.

Archibald, J. M. (2015): Endosymbiosis and eukaryotic cell evolution. Curr Biol., 25: R911-R921.

Aschenbach, J., Penner, G., Stumpff, F. and Gäbel, G. (2011): Ruminant nutrition symposum: Role of fermentation acid absorption in the regulation of ruminal pH. J. Anim. Sci., 89: 1092-1107.

Babic, A., Berkmen, M., Lee, C. and Grossman, A. (2017): Efficient Gene Transfer in Bacterial Cell Chains. mbio., 2:2-11

Bernalier, A., Fonty, G., Bonnemoy, F. and Gouet, P. (1992): Degradation and fermentation of cellulose by the rumen anaerobic fungi in axenic cultures or in association with cellulolytic bacteria. Curr. Microbiol., 25: 143-148.

Brooker, J. D. and McCarthy, J. M. (1997): Gene knockout of the intercellular amylase gene by homologous recombination in streptococcus bovis. Curr. Microbial., 35: 133-138.

Brooker, J. D., Lum, A. M. and Ward, H. M. (1995): A gene targeting suicide vector for streptococcus bovis. Lett. Appl. Microbial., 21: 292-297.

Brown, M., Ponce, C., Pulikanti, R. (2006): Adaptation of beef cattle to high-concentrate diets: performance and ruminal metabolism. J. Anim. Sci., 84: 25-33.

Burns, J. C. (2008): ASAS Centennial Paper: utilization of pasture and forages by ruminants: a historical perspective. J. Anim. Sci., 86: 3647-3663.

Burrus, V. and Waldor, M. (2004): Shaping bacterial genomes with integrative and conjugative elements. Res. Microbiol., 155: 376-386.

Chen, I. and Dubnau, D. (2004): DNA uptake during bacterial transformation. Nature Rev. Microbiol., 2: 241249. 
Cohen, S. N. (1976): Transposable genetic elements and plasmid evolution. Nature., 263: 731-738.

Cole, N. A., McLaren, J. B. and Hutcheson, D. P. (1982): Influence of Preweaning and B-Vitamin Supplementation of The Feedlot Receiving Diet on Calves Subjected to Marketing and Transit Stress. $J$. Anim. Sci., 54:911-917.

Cotta, M. A. (1988): Amylolytic activity of selected species of ruminal bacteria. Appl. Environ. Microbiol., 54: 772-776.

Counotte, G. and Prins, R. (1981): Regulation of lactate metabolism in the rumen. Vet. Res. Commun., 5: 101115.

Couturier, M., Bex, F., Bergquist, P. and Maas, W. (1988): Identification and classification of bacterial plasmids. Microbiol. Rev., 52: 375-395.

Creevey, C., Doerks, T., Fitzpatrick, D., Raes, J. and Bork, P. (2011): Universally distributed single-copy genes indicate a constant rate of horizontal transfer. PLoS One.; 6 doi: 10.1371/journal.pone.0022099.

Dashtban, M., Schraft, H. And Qin, W. (2009): Fungal bioconversion of lignocellulosic residues; opportunities \& perspectives. Int. J. Biol. Sci., 5: 578-595

Del Solar. G., Giraldo, R., Ruiz-Echevarría, M., Espinosa, M. and Díaz-Orejas, R. (1998): Replication and control of circular bacterial plasmids. Microbiol. Mol. Biol. Rev., 62: 434-64.

Dobrindt, U., Hochhut, B., Hentschel, U. and Hacker, J. (2004): Genomic islands in pathogenic and environmental microorganisms. Nature Rev. Microbiol., 2: 414-424.

Duskova, D. and Marounek, M. (2001): Fermentation of pectin and glucose, and activity of pectin-degrading enzymes in the rumen bacterium Lachnospira multiparus. Lett. Appl. Microbiol., 33: 159-163.

Edwards, J. E., Huws, S. A., Kim, E. J. and Kingston-Smith, A. H. (2007): Characterization of the dynamics of initial bacterial colonization of nonconserved forage in the bovine rumen. FEMS Microbiol. Ecol., 62: 323335.

Flint, H. J. and Thomson, A. M. (1990): Deoxyribonuclease activity in rumen bacteria. Lett. Appl. Microbiol., 11: $18-21$

Flint, H., Derry, K., Mercer, C., Melville, K. and Scott, P. (1999): Natural genetic transformation in the rumen bacterium Streptococcus bovis JB1 Rowett Research Institute, Greenburn Road, Bucksburn, Aberdeen AB21 9SB, UK, Received 10 August 1999; received in revised form 26 August, 1999; accepted 27 August.

Foreberg, C. W., Cheng, K. J. and White, B. A. (1997): polysaccharide degradation in the rumen and large intestine. In: Gastrointestinal Microbiology. Mackie, R.I. and White, B.A. ( Ed). Chapman and Hall. New York. Pp. 319-379.

Fournier, G. P. and Gogarten, J. P. (2007): Evolution of acetoclastic methanogenesis in Methanosarcina via horizontal gene transfer from cellulolytic clostridia. J. Bacteriol., 190: 1124-1127.

Fournier, G., Huang, J. and Gogarten, J. (2009): Horizontal gene transfer from extinct and extant lineages: biological innovation and the coral of life. Philos. Trans. R. Soc. B. Biol. Sci.., 364: 2229-2239.

Frost, L., Leplae, R., Summers, A. and Toussaint, A. (2005): Mobile genetic elements: the agents of open source evolution. Nat. Rev. Microbiol., 3: 722-732.

Fuentes, M., Calsamiglia, S., Cardozo, P. and Vlaeminck, B. (2009): Effect of pH and level of concentrate in the diet on the production of biohydrogenation intermediates in a dual-flow continuous culture. J. Dairy Sci., 92: 4456-4466.

Garcia-Vallve, S., Romeu, A., Palau, J. (2000): Horizontal gene transfer of glycosyl hydrolases of the rumen fungi. Mol. Biol. Evol., 17:352-361.

Gilmour, M., Mitchell, W. and Flint, H. (1996): Genetic transfer of lactet utilizing ability in rumen bacterium selenonas ruminantium. Lett. Appl. Microbial., 22: 52-56.

Gregg, K. (1995): Engineering gut flora of ruminant livestock to reduce forage toxicity: progress and problems, Trends Biotechnol., 13: 418-421.

Hall, R. M. and Collis, C. M. (1995): Mobile gene cassettes and integrons: capture and spread of genes by sitespecific recombination. Mol. Microbiol., 15: 593-600.

Henriksen, S. and Henrichsen, J. (1975): Twitching motility and possession of polar fimbriae in spreading Streptococcus sanguis isolates from the human throat. Acta Path. Microbiol. Scand. Sect. B., 83:133-140.

Hodrova, B., Kopecny, J. and Petr, O. (1995): Interaction of the rumen fungus Orpinomyces joyonii with Megasphaera elsdenii and Eubacterium limosum. Lett. Appl. Microbiol. 21: 34-37.

Ivan, M., Petit, H., Chiquette. J. and Wright, A. (2012): Rumen fermentation and microbial population in lactating dairy cows receiving diets containing oilseeds rich in C-18 fatty acids. Br. J. Nutr., 31: 1-8.

Jenkins, T. C., Wallace, R. J., Moate, P. J. and Mosley, E. E. (2008): Board-invited review: Recent advances in biohydrogenation of unsaturated fatty acids within the rumen microbial ecosystem. J. Anim. Sci., 86: $397-$ 412

Johnson, K. A., and Johnson, D. E. (1995): Methane emissions from cattle. J. Anim. Sci., 73: 2483-2492.

Kingston-Smith, A. H., Marshall, A. H. and Moorby, J. M. (2012): Breeding for genetic improvement of forage 
plants in relation to increasing animal production with reduced environmental footprint. Animal 1:1-10.

Ku, C., Nelson-Sathi, S., Roettger, M., Sousa, F., Lockhart, P., Bryant, D., Hazkani-Covo, E., McInerney, J., Landan, G. and Martin, W. (2015): Endosymbiotic origin and differential loss of eukaryotic genes. Nature, 524: 427-432.

Lorenz, M. and Wackernagel, W. (1994): Bacterial gene transfer by natural genetic transformation in the environment. Microbiol. Rev., 58: 563-602.

Madigan, Martino and Parker, (2000): Brock Biology of Microorganisms, $10^{\text {th }}$ editon. P rentice Hall, publishes, UK.

Marounek, M. and Kalachnyuk, G. (1995): Stoichiometry of pectin and glucose fermentation in Prevotella ruminicola. Pub, Med., 67: 107-10.

Martín, M., José, L. and García.P (2010): DNA Transposons: Nature and Applications in Genomics. current genomics, 11: 115-128.

Matassi, G. (2017): Horizontal gene transfer drives the evolution of Rh50 permeases in prokaryotes. BMC Evol. Biol., 17: 2.

McAllister, T. A., Rode, L. M., Major, D. J., Cheng, K. J. and Buchanan-Smith, J. G. (1990): Effect of ruminal microbial colonization on cereal grain digestion. Can. J. Anim. Sci., 70: 571-579.

Michalet-Doreau, B., Fernandez, I. and Fonty, G. (2002): A comparison of enzymatic and molecular approaches to characterize the cellulolytic microbial ecosystems of the rumen and the cecum. J. Anim. Sci., 80: 790-796.

Moniello, G., Richardson, A., Duncan, S. and Stewart, C. (1996): Effects of coumarin and sparteine on attachment to cellulose and cellulolysis by Neocallimastix frontalis RE1. Appl. Environ. Microbiol., 62: 4666-4668.

Morrison, M. (1996): Do ruminal bacteria exchange genetic material. J. Dairy Sci., 79:1476-1486.

Oltjen, J. and Beckett, J. (1996): Role of ruminant livestock in sustainable agricultural systems. J. Anim. Sci., 74: 1406-1409.

Ozutsumi, Y., Tajima, K., Takenaka, A. and Itabashi, H. (2005): The effect of protozoa on the composition of rumen bacteria in cattle using 16S rRNA gene clone libraries. Biosci. Biotechnol. Biochem., 69: 499-506.

Pawel, M. P., Okorieb, A. U. and Peter, J. B. (1981): Ammonia Concentration and Protein Synthesis in the Rumen. Sci. Food Agric., 32: 159-766.

Peterka, M., Accetto, T. and Avgustin, G. (2000): horizontal gene transfer in bacteria. Review paper on an ecological and evolutionary perspective, 76: 163-169.

Pitta, D., Pinchak, E., Dowd, S., Osterstock, J., Gontcharova, V., Youn, E., Dorton, K., Yoon, I., Min, B., Fulford, J., Wickersham, T. and Malinowski, D. (2010): Rumen bacterial diversity dynamics associated with changing from bermudagrass hay to grazed winter wheat diets. Microb. Ecol., 59: 511-522.

Russell, J. B. and Mantovani, H. C. (2002): The bacteriocins of ruminal bacteria and their potential as an alternative to antibiotics. J. Mol. Microbiol. Biotechnol., 4: 347-355.

Russell, J. B. and Rychlik, J. L. (2001): Factors that alter rumen microbial ecology. Science, 292: 1119-1122.

Russell, J. B., Sharp, W. M. and Baldwin, R. L. (1979): The effect of pH on maximum bacterial growth rate and its possible role as a determinant of bacterial competition in the rumen. J. Anim. Sci., 48: 251-255.

Schönknecht, G., Weber, A. P. and Lercher, M, J. (2014): Horizontal gene acquisitions by eukaryotes as drivers of adaptive evolution. Bioessays, 36: 9-20.

Scott, K. P., Barbose, T. M., Forbes, K. J. and Flint, H. J. (1997): High frequency transfer of naturally occurring chromosomal tetracycline resistance element in ruminal anaerobic Butyrivibrio fibrisolvens. microbial., 63: 3405-3411.

Selinger, L. B., Forsberg, C. W. and chang, K. J. (1996): The rumen: A unique source of enzyme for enhancing livestock production. .Anaerobe., 2: 263-284.

Shoemaker, N., Nicolich, M., Hong, G. and Salyers, A. (1994): Evidence for natural horizontal transfer of tetQ between bacteria that normally colonize human and bacteria that normally colonize livestock. Appl. Environ. Microbiol., 60: 3255-3260.

Sirohi, S. K., Choudhury, P. K. and Dagar, S. S. (2012): Isolation, characterization and fibre degradation potential of anaerobic rumen fungi from cattle. Ann. Microbiol., 63:1187-1194.

Smith, H. O., Danner, D. B. and Deich, R. A. (1981): Genetic transformation. Annu. Rev. Biochem., 50: 41-68.

Sofya, K. G., Marat, D. K. and Mikhail, S. G. (2015): Horizontal gene transfer and genome evolution in Methanosarcina. BMC Evol. Biol., 15:102.

Sparks, R. W. and Connor, E. E. (2011): Dynamics of the rumen microbiota. In: Metagenomics and its Applications in Agriculture, Biomedicine and Environmental Studies, Li, R. W. (ed.), Nova Science, New York, Pp. 135-164.

Stewart, P., Byram, R., Grimm, D., Tilly, K. and Rosa, P. (2005): The plasmids of Borrelia burgdorferi: essential genetic elements of a pathogen. Plasmid, 53: 1-13.

Syvanen, M. (2012): Evolutionary implications of horizontal gene transfer. Annu. Rev. Genet., 46: 341-358. 
Tharwat, M. Al-Sobayil, F., Ali, A. and Buczinski, S. (2012): Transabdominal ultrasonographic appearance of the gastrointestinal viscera of healthy camels (Camelus dromedaries). Res. Vet. Sci., 93: 1015-1020.

Tompkins L. (1985): DNA methods in clinical microbiology. In: Lenette EH, Manual of clinical microbiology $4^{\text {th }}$ edition, Washington D.C. American Society for Microbiology, 10: 23-28.

Wackernagel, W. and Brigulla, M. (2010): Molecular aspects of gene transfer and foreign DNA acquisition in prokaryotes with regard to safety issues. Applied Microbiology and Biotechnology, 86: 1027-1041.

Waldor, M., Friedman, D. and Adhya, S. (2005): Phages: their Role in Bacterial Pathogenesis and Biotechnology. ASM Press, Washington D.C.

Weimer, P. J. (1996): Why Don’t Ruminal Bacteria Digest Cellulose Faster? J. Dairy Sci., 79: 1496-1502.

Willetts, N. and Skurray, R. (1980): The Conjugation System of F-Like Plasmids. Annual Review of Genetics, 14: 41-76.

Willetts, N. and Wilkins, B. (1984): Processing of plasmid DNA during bacterial conjugation. Microbiol. Rev., 48: $24-41$

Wommack, K. E. and Colwell, R. R. (2000): Virioplankton: viruses in aquatic ecosystems. Microbiol. Mol. Biol. Rev., 64: 69-114.

Wozniak, R. A. and Waldor, M. K. (2010): Integrative and conjugative elements: mosaic mobile genetic elements enabling dynamic lateral gene flow. Nat. Rev. Microbiol., 8: 552-563.

\section{Internet References}

http://bio.libretext.org/TextMap/Map\%3A-Microbiology-(Kaiser)/Unit-2\%3A-Bacteial-Genetics-and-thechemical-control-of-bacteria/3\%3A-Bacterial-Genetics/3.1\%3A-Horizonal-Gene-Transfer-in-bacteria Accessed on 9 April, 2017.

http://en.m.wipiedia.org/wiki/File:Transduction-illusteration.pdf Accessed on: April 15, 2017. http://www.slideshare.net/mobile/doctorrao/bacteriophages Accessed on 10April, 2017

http:/biologyboom.com/conjugation-gene-recmbination-in-e.coli. Accessed on 22 March,2017

https://www.boundless.com/microbiology/textbooks/boundless microbiology textbook /microbial-genetics-

7/genetic-transfer-in-prokaryotes-81/bacterial-transduction-443-6859/) Accessed on 27 March, 2017.

https://www.ebi.ac.uk/interpro/potm/2006 12/Page2.htm Accessed on 3 April, 2017.

Table 1. List of bacteria and their fermentation products in the rumen

\begin{tabular}{|c|c|c|c|}
\hline Bacteria & Fermentation products & & Reference \\
\hline & Cellulose-degrading bacteria & & \\
\hline Fibrobacter succinogenes & Succinate, Acetate, Formate & & Ivan et al., 2012 \\
\hline Butyrivibrio fibrisolvens & $\begin{array}{l}\text { Acetate, Formate, Lactate, Butyrate, } \\
\mathrm{CO} 2\end{array}$ & $\mathrm{H} 2$ & Weimer, 1996 \\
\hline Ruminococci albus & Acetate, Formate, $\mathrm{H} 2, \mathrm{CO} 2$ & & Michalet-Doreau et al., 2002 \\
\hline Clostridium lochheadii & $\begin{array}{l}\text { Acetate, Formate, Butyrate, } \mathrm{H} 2, \mathrm{CO} 2 \\
\text { Amylolytic bacteria }\end{array}$ & & Weimer, 1996 \\
\hline Bacteriodes ruminicola & Formate, Acetate, Succinate & & Cotta, 1988 \\
\hline Selenomonas ruminantium & Acetate, Propionate, Lactate & & $\begin{array}{l}\text { Cotta, } 1992 \\
\text { Cotta, 1988; McAllister }\end{array}$ \\
\hline Streptococci bovis & $\begin{array}{l}\text { Lactate } \\
\text { Lactate-degrading bacteria }\end{array}$ & & et al., 1990 \\
\hline Selenomonas lactilytica & $\begin{array}{l}\text { Acetate, Succinate } \\
\text { Pectin-degrading bacteria }\end{array}$ & & Brown et al., 2006 \\
\hline Lachnospira multiparus & $\begin{array}{l}\text { Acetate, Formate, Lactate, } \mathrm{H} 2, \mathrm{CO} 2 \\
\text { Ruminal archaea (methanogens) }\end{array}$ & & Duskova and Marounek, 2001 \\
\hline $\begin{array}{l}\text { Methanobrevibacter } \\
\text { Ruminantium }\end{array}$ & $\mathrm{CH} 4$ of $\mathrm{H} 2+\mathrm{CO} 2$ or Formate & & $\begin{array}{l}\text { Yanagita et al., 2000; } \\
\text { Hook et al., } 2010\end{array}$ \\
\hline Megasphaera elsdenii & $\begin{array}{l}\text { Lactic acid-utilizing bacteria } \\
\text { Lactate }\end{array}$ & & Counotte and Prins, 1981 \\
\hline
\end{tabular}

Table 2: List of common rumen fungi

\begin{tabular}{lll}
\hline Cellulolytic fungi & Fermentation products & Reference \\
\hline Neocallimastix frontalis & Lactate, Formate, Acetate, Succinate, Ethanol & Moniello et al., 1996 \\
Piromyces communis & Celobiose, celooligosacarides & Dashtban et al., 2009) \\
Orpinomyces joyoni & Glucose & Hodrova et al., 1995) \\
\hline
\end{tabular}




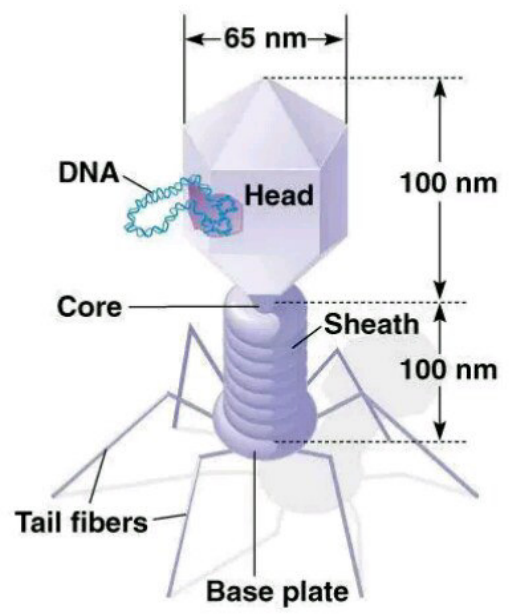

Figure 1: Bacteriophage and its structural parts

Source: http://www.slideshare.net/mobile/doctorrao/bacteriophages

1)

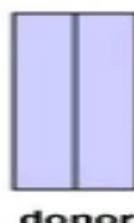
endonucleas inserts nick.

donor

DNA

donor

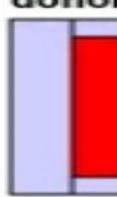

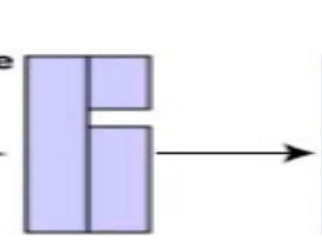
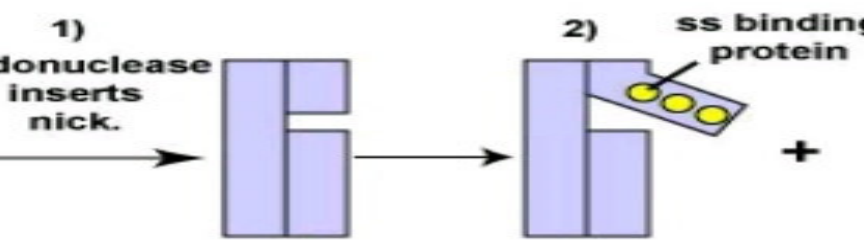

3) Rec $A$ protein

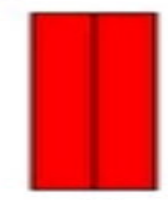
recipient

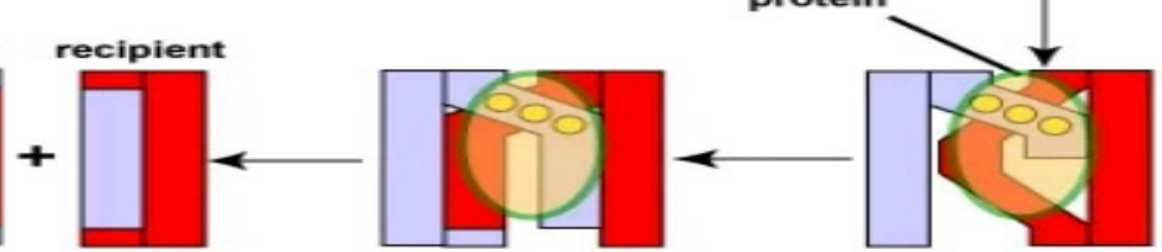

4) crossing over, breakage, and reunion

Figure 2: Natural genetic transformation

Source: http://bio.libretext .org/TextMap/Map\%3A-Microbiology-(Kaiser)/Unit-2\%3A-Bacteial-Genetics-andthe-chemical-control-of-bacteria/3\%3A-Bacterial-Genetics/3.1\%3A-Horizonal-Gene-Transfer-in-bacteria 


\section{TRANSDUCTION PROCESS}

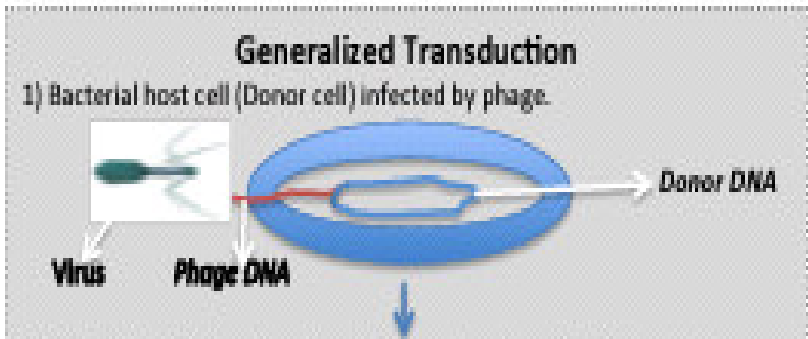

2) Host cell DNA is brokm down into smallex pisces. Proteins and phage DNA is ako snthesied.

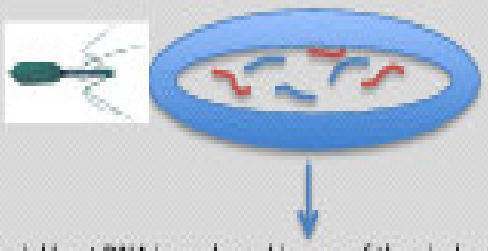

3) Hacterial host DNa is packaged in one of the viral capaids that are released through lysis of the bacterial cell.

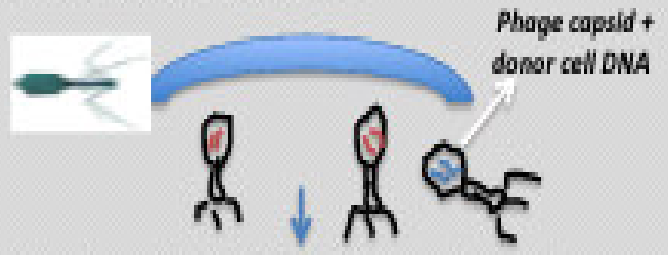

4) Tranduing physe with host DNA infost new rocipient cell. Rocombination also accurs here.

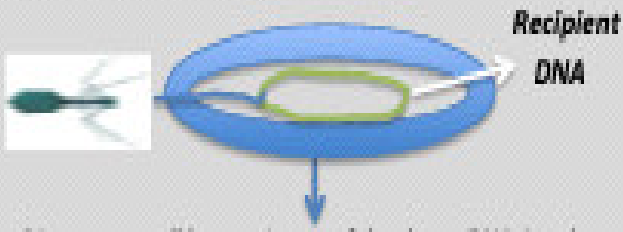

5) Hecombinant new cell has a mixture of the danor DNA 1 and one of its own DNA lis genatye is different.

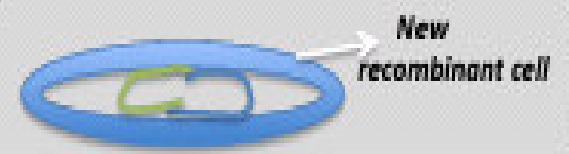

\section{Specialized Transduction}

1) Prophage DHA integrated into the bacterial DNA.

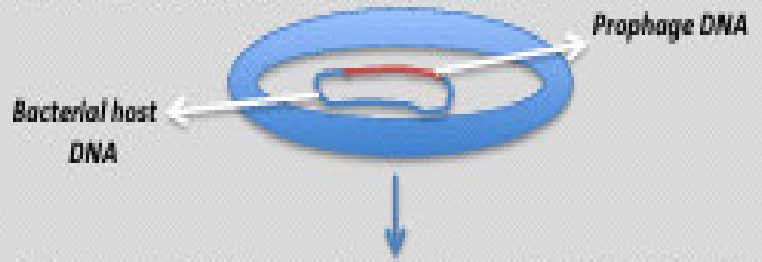

2) Prophage DNA cuts incorrectly and ochanges its DNA to that of bacterial host call.

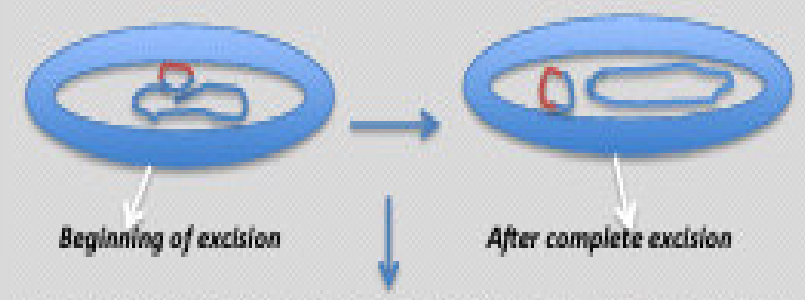

3) Phage capsids contain bacterial host DNA, which is is tranterred to a new bacteral recipient cell.

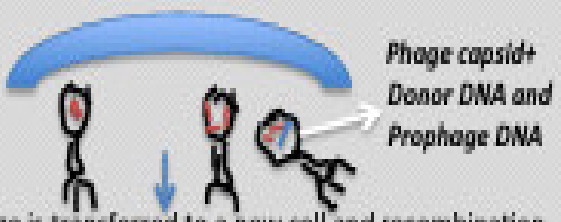
4) Transduced phage is transferred to a new cell and recombination octurs.

\section{Rexiplent DNA}
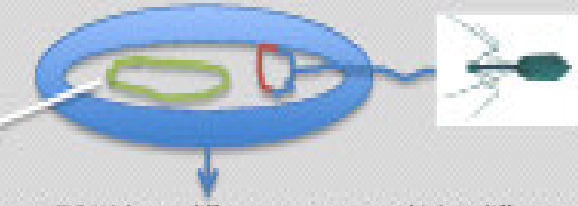

5) The recombinant call bNa has a different genatype, which is different from the danor or rexipient cell gonatype.

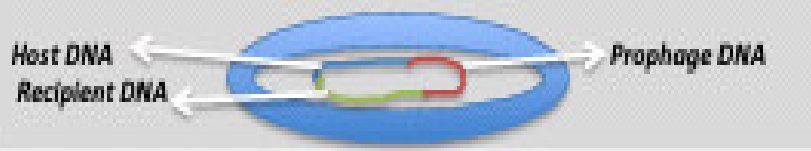

Figure 3: Gene transfer by transduction

Source: http://en.m.wipiedia.org/wiki/File:Transduction-illusteration.pdf 
Copyright $\bigcirc$ The McGraw-Hill Companies, Inc. Permission required for reproduction or display.

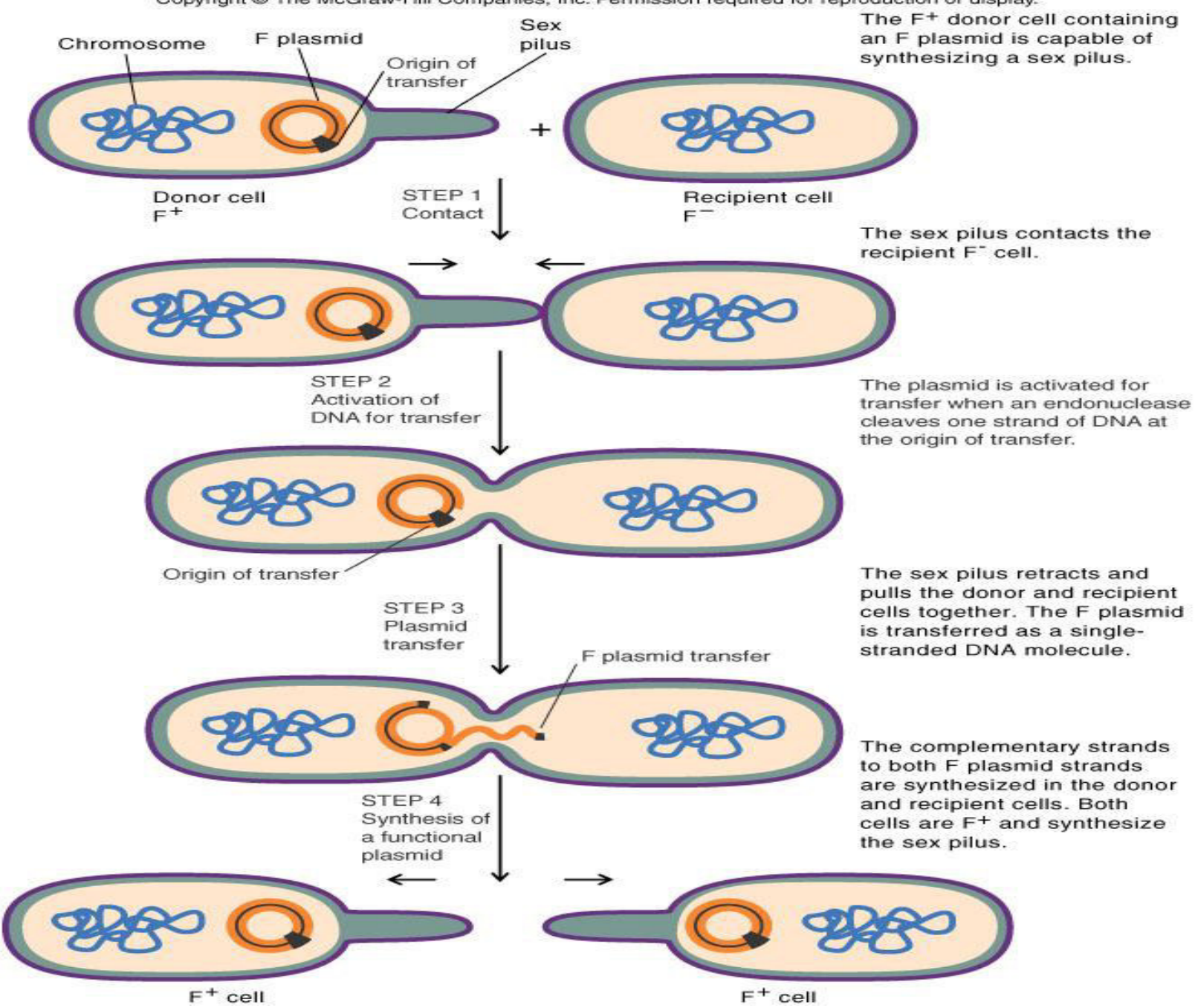

Figure 4: Gene transfer by conjugation

source: http:/biologyboom.com/conjugation-gene-recmbination-in-e.coli 